\title{
Increasing science literacy in optics and photonics through science centers, museums, and web-based exhibits
}

\section{Stephen Pompea, Isabel Hawkins}

Stephen M. Pompea, Isabel Hawkins, "Increasing science literacy in optics and photonics through science centers, museums, and web-based exhibits," Proc. SPIE 4588, Seventh International Conference on Education and Training in Optics and Photonics, (28 May 2002); doi: 10.1117/12.468750

SPIE Event: Education and Training in Optics and Photonics 2001, 2001, Singapore, Singapore 


\title{
Increasing Science Literacy in Optics and Photonics through Science Centers, Museums, and Web-based Exhibits
}

\author{
Stephen M. Pompea and Isabel Hawkins ${ }^{\mathrm{b}}$ \\ ${ }^{a}$ Pompea \& Associates, Tucson, Arizona ${ }^{1}$ \\ ${ }^{\mathrm{b}}$ Center for Science Education, Space Sciences Laboratory, University of California, Berkeley ${ }^{2}$
}

\begin{abstract}
Exhibits and programs at hands-on science centers, museums, and on the web can be used to increase science literacy in optics and photonics. These informal science education efforts play a profound role in increasing the public's understanding of optics and photonics and its applications. Informal science education also plays a significant role in interesting young children in the photonics field. This paper presents a tour of the informal science education world and describes how scientists can work with science centers. It also describes how science centers and museums have made use of web broadcasts of special events such as eclipses to enhance public interest in science topics.
\end{abstract}

Keywords: optics education, museums, science centers, exhibits, webcasts

\section{INTRODUCTION}

Informal science education may be defined as all science education that takes place outside of the formal school classroom. In this definition, informal science education includes science education taking place in museums, hands-on science centers, children's museums, planetaria, through mass media, in live and film theatres, and in exhibits in the lobbies of public buildings. Science centers in particular have proven to be an effective vehicle to relay the excitement of science. ${ }^{1}$ Museums have also become vehicles for displaying the magic of light and color in a more serene setting. ${ }^{2}$ This paper will provide a tour of science centers and describe what they can offer in the field of optics and photonics education. More importantly, this paper will briefly describe how optics professionals and professional optics educators can best work with informal institutions, which have a profoundly different culture than the university, research laboratories, or formal secondary education institutions. Many of the illustrations given will not be optics examples, but the reader can easily think of optics-related examples.

\section{TYPES OF INFORMAL INSTITUTIONS}

Some of the most common institutions that promote science are:

- Natural History and Science Museums: They often have a balance of static and activity oriented exhibits.

- Hands-on science-technology centers: They often have predominately activity oriented exhibits referred to as "hands-on" exhibits. Science technology centers are often large urban institutions with a multitude of exhibits and programs geared for all ages. Examples: Exploratorium in San Francisco, Pacific Science Center in Seattle, Experimentarium in Copenhagan, St. Louis Science Center.

- Children's museums: Activity-based museums usually that are not science-theme oriented. Examples: San Jose

\footnotetext{
${ }^{1}$ Science Education Consultant, 1321 East Tenth Street, Tucson AZ 85719-5808 Also Education Co-Chair, Arizona Optics Industry Association and Adjunct Faculty, University of Arizona, Telephone 520.792.2366 Email:spompea@pompea-associates.com

2 Director, Center for Science Education at the Space Sciences Lab, MC 7450, Grizzly Peak @ Centennial Drive, Berkeley, CA 94720-7450 Telephone 510.643.5662, isabelh@ssl.berkeley.edu, http://cse.ssl.berkeley.edu/isabel

We acknowledge the support of the NASA Office of Space Science Sun-Earth Connection Education Forum
} 
Children's Museum, Indianapolis Children's Museum, Boston Children's Museum.

- Planetaria: Numerous small and large planetaria deal with optics themes, usually as part of astronomy.

Examples, Hayden Planetarium in New York City and Holt Planetarium at Lawrence Hall of Science in Berkeley.

- Media and Web-based exhibits: Web broadcasts of scientific events. This approach has been pioneered by the Exploratorium in San Francisco.

- Large format theatres (usually in science centers): These show specially made movies, often on nature and science topics.

\section{A QUICK TOUR OF SCIENCE CENTERS}

Science centers are usually located near population centers and range from small facilities to those that are several stories high and cover several city blocks. Most science centers use their outdoor space for exhibits, and these areas are very appropriate for optics exhibits. For example, Flandrau Science Center in Tucson uses the space just below the planetarium dome for a diffraction grating-part of the center's optics exhibits. Dr. Stephen Jacobs of the University of Arizona's Optical Sciences Center has worked with Flandrau for many years to assist in the creation of optics-related exhibits.

The photograph below shows a special outdoor exhibit-the largest single piece rectangular sundial in the country, built by noted sundial artist John

Carmichael. Sculptural

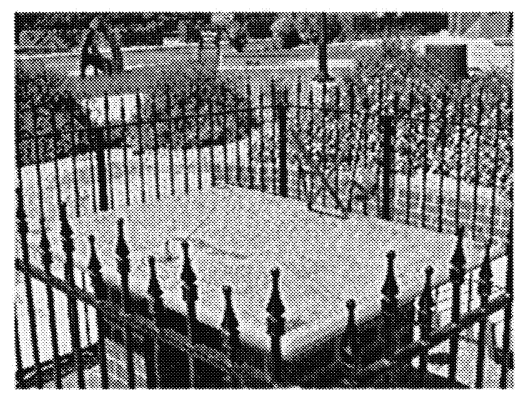
exhibits can be very large in size, such as a DNA metal sculpture at Lawrence Hall of Science.

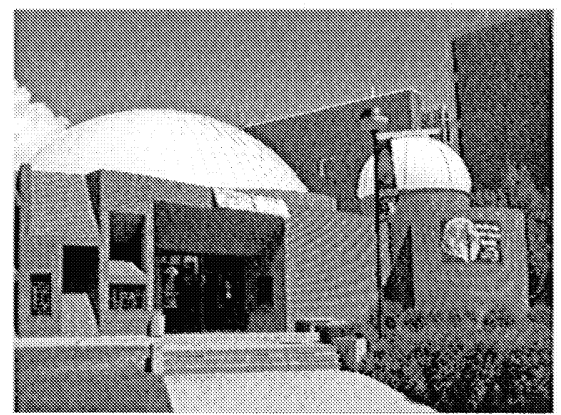

Most outside exhibits are meant to be interactive, if only in the sense that a visitor can play on it or observe it from different directions. Some are dynamic-moved by the wind or the visitor. The outside area of a science center is an extremely important area and in fact some science centers are best known by their outside "icon" exhibits, such as the DNA structure at Lawrence Hall of Science, shown below.

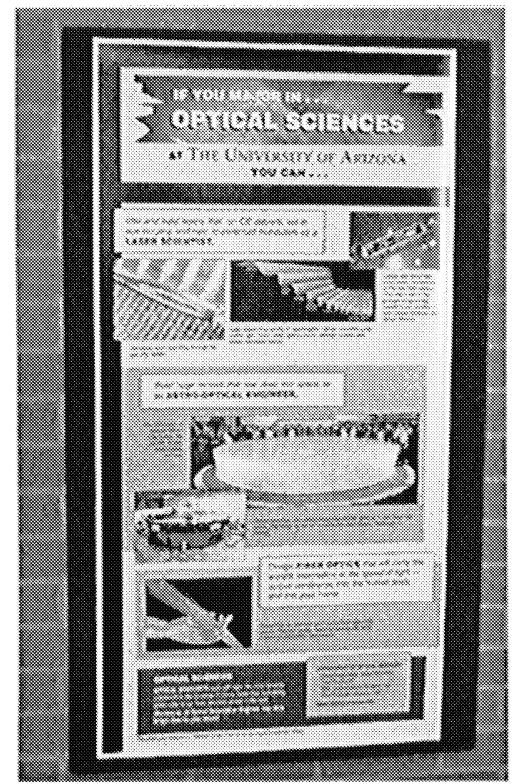

Inside the science center, exhibits may be either active (hands-on) or static. This distinction is not always a clear-cut one. The poster on optics education is attractive, easy to read, and friendly in its tone.

However, there is little that one can do with it besides read it. In contrast, across from it is

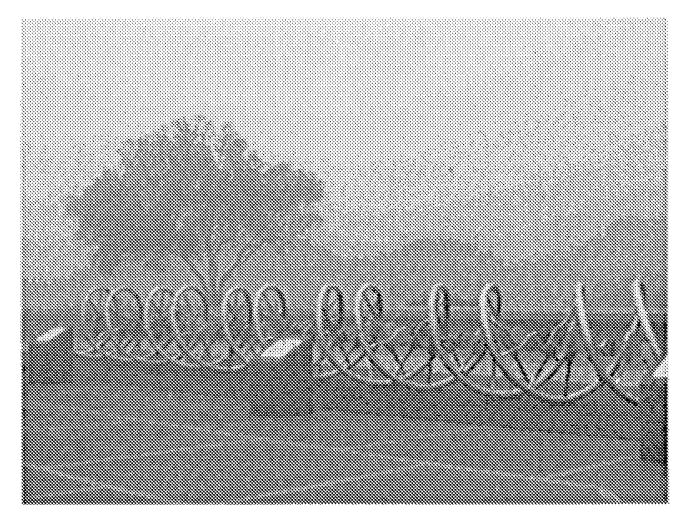
an exhibit on stereo viewing of Mars using colored glasses. This one would be classified as interactive. The visitor must notice how the exhibit is set up and take the action pick up the colored glasses to view the photo on the wall. In all likelihood the visitor will take some time to be able to appreciate the 3-D effect. Another interactive exhibit is a hologram called "The Kiss", shown to 


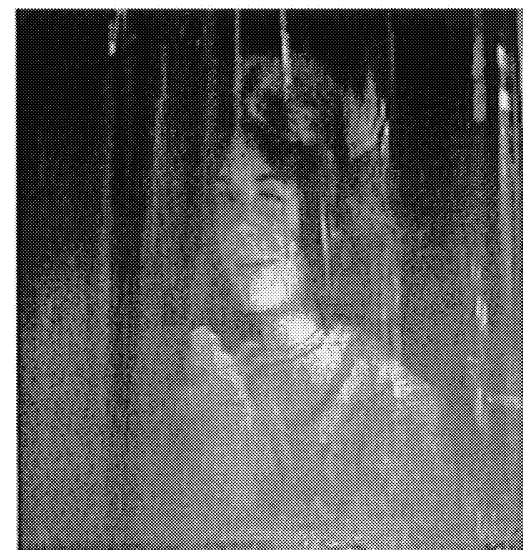

trajectory of a spacecraft. the left. As the visitor walks by a hologram of a women blows a kiss and winks. If the visitor stops, the motion stops. This exhibit also illustrates a very fundamental aspect of exhibit design. Because of the nature of the hologram, this exhibit can only be seen from a height similar to the level of the hologram. Small children cannot see the exhibit, nor can extremely tall people. Considerable effort goes into each exhibit in order to try to find the right audience or to appeal to as wide an audience as possible. In the end, there is still a preferred audience for most exhibits, or sometimes a preferred height for the audience.

Some exhibits are found in building lobbies. In some cases the demonstrations and displays used for conferences and meetings are placed in the lobby where visitors can appreciate them as well. A display on an ultraviolet spacecraft is shown in the lobby of the Space Sciences Lab at UC Berkeley in the illustration on the right side. On the floor of the lobby (left below) is a permanent exhibit on the

Many exhibits are housed in equally non-traditional locations. A recent traveling exhibit on Mars sponsored by a Children's Museum was place in a suburban shopping mall. This location was successful as it attracted visitors that may not regularly venture downtown to the Children's Museum. Parking at the mall was plentiful, a key issue for any science center or museum.
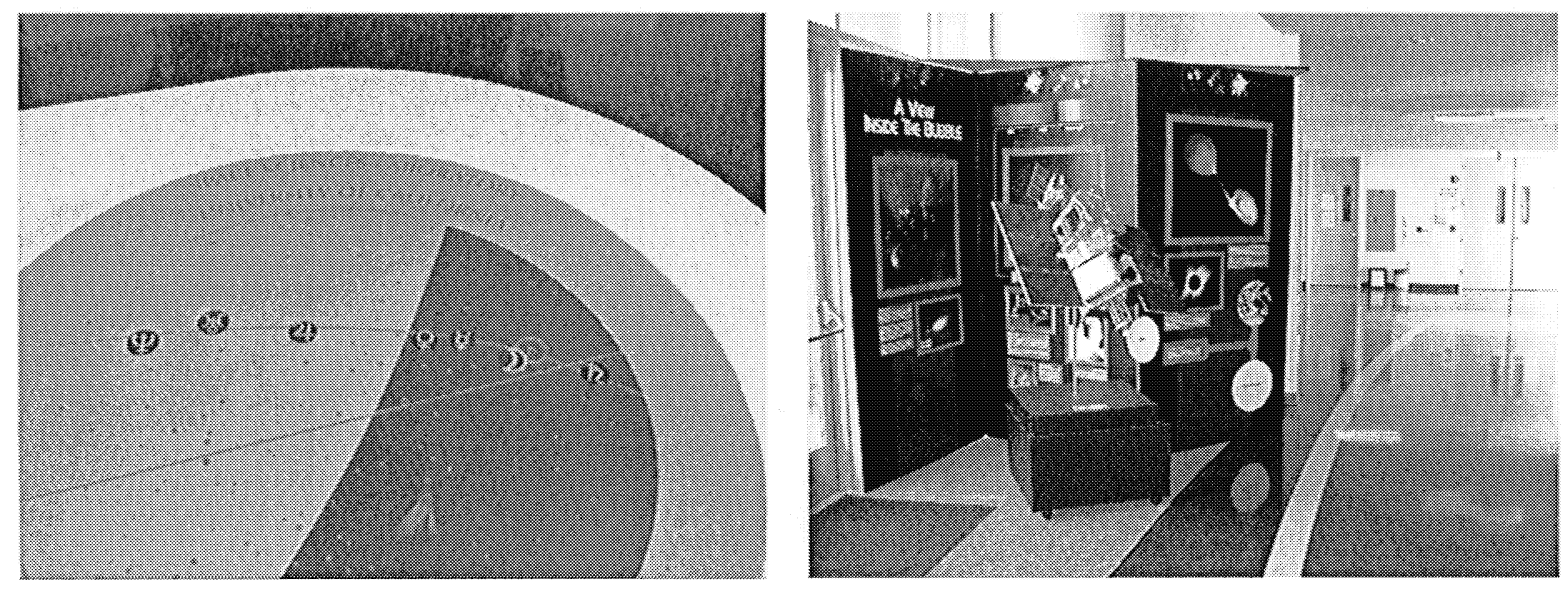

\section{OPTICS AND EXHIBITS}

Although this paper will not discuss the wide variety of fine optics exhibits in museums and science centers around the world, a few examples will be discussed in order to highlight the attributes of good optics exhibits. Some examples of interactive optics exhibits that have proven popular and are educationally valuable can be found in Berkeley and Tucson. On the right is an optics mirror exhibit at the Lawrence Hall of Science in Berkeley. It uses a large mirror where the visitor can shake hands with themselves. The photograph shows the image waiting to touch your real hand. This exhibit is excellent as it embodies many elements of good exhibit design. The mirror and signage is shown below.

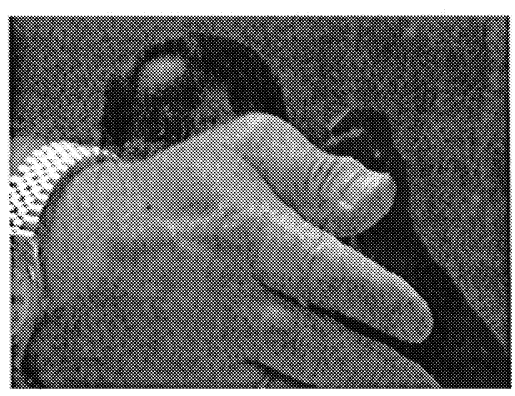


Good exhibits like this one have a number of characteristics. These memorable exhibits are:

- Interesting-they have a wide appeal.

- Illustrative of an important principle-they have appeal to educators.

- Durable-they don't need to be fixed often.

- Inexpensive-development may be expensive, but many use simple materials.

- Nearly age independent-have value for patrons of all ages, with perhaps a different appeal for each group.

- Interactive-require the visitor to do something and think.

- Not reliant on extensive reading or following instructions-research has shown that many people don't read or follow directions.

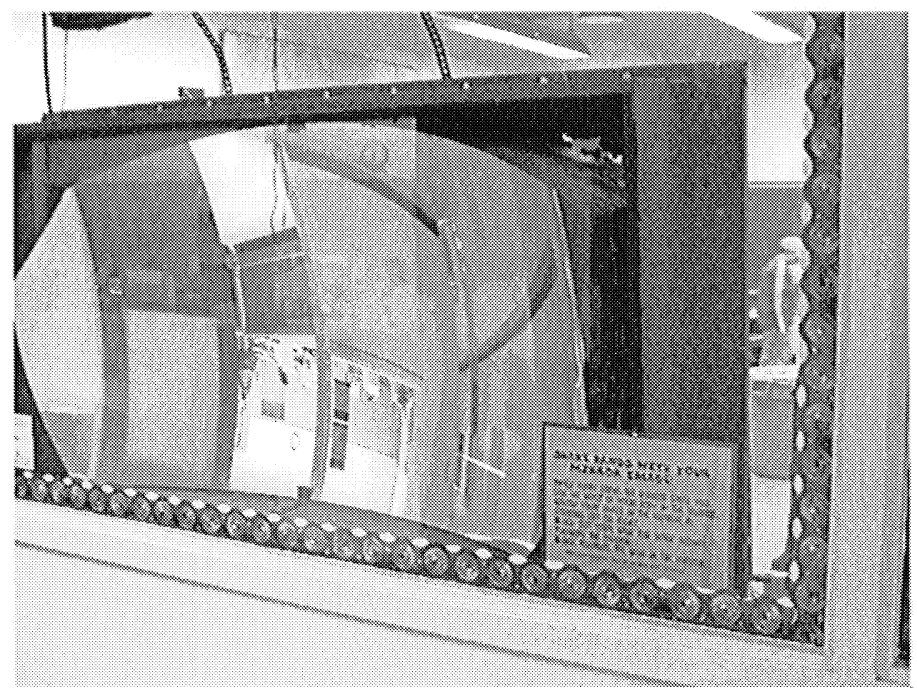

Another excellent exhibit, of greater complexity, is the solar spectrum exhibit at Flandrau Science Center, shown below. It uses a heliostat on the roof to track the Sun, and then projects the sunlight through a roof opening to a mirror/grating arrangement. The spectrum is projected in a way where solar absorption lines can be easily seen.

Some of this exhibit's best features are that it is colorful, attractive, and illustrates a fundamental scientific principle. Like nearly all other science center exhibits, the exhibit exists in the larger museum context. The context of the exhibit is shown in the illustration seen below on the right. The solar spectrum exhibit is approachable mainly from one direction and the visitor must negotiate movement around several other exhibits to get to it. Although such a fine exhibit would look good by itself in the middle of an empty floor, the reality of museums is very different. It is one of many exhibits and surrounded by many unrelated exhibits. This common context must be taken into account in the design of exhibits.



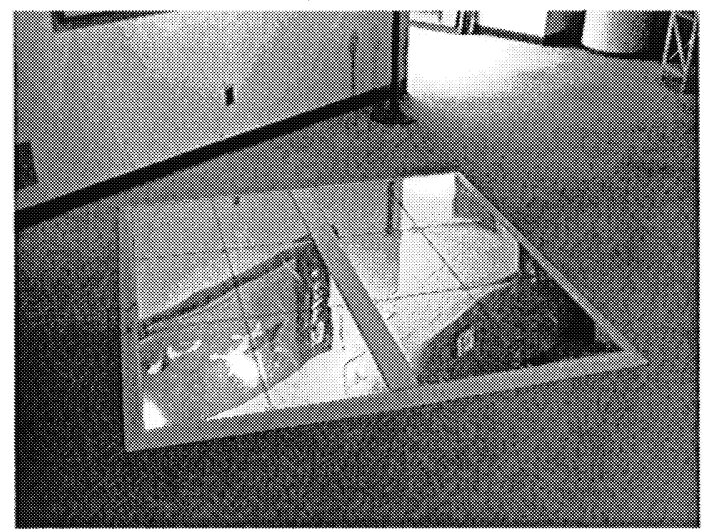

Not all optics exhibits are as single purpose as these two examples on mirrors and solar spectra. Perhaps, the first step to getting more optics into a science center might be to examine exhibits and programs at the center on other subjects and see if they utilize optics or optics principles. Optical concepts in these exhibits can then be reinforced. In injecting more optics into science centers, the optics professional should pay careful attention to decidedly non-optics exhibits where a point about optics can be made. For example, the floor area with mirrors shown here is part of an exhibit on human movement where the visitor might dance or move. Further information on mirrors could be provided. A NASA Moon rock exhibit that has a magnifying glass is another example where optical explanations can be given. Optics can be worked into these exhibits through extra written material (signage) around the exhibit, through a printed visitor's guide, or through a teacher's guide.

\section{WEB-BASED EVENTS}

A final, very important area for informal education is the Internet and world-wide web. A variety of web-based products from informal science institutions have enhanced their educational effectiveness. Web-based educational activities, interactive exhibits, and teacher guides to exhibits have all proved extremely valuable. One particular activity with great potential is the use of web-based events to bring a topical area into prominence. The event can be broadcast over the Internet by a science center. The audience may be visitors at other science centers watching the event or members of the public accessing the event through their computer. The science center plays the host role for events that are happening remotely and can send a video team to cover the event. The science center can also build educational materials around the event and create an opportunity for live questions and answers about the event. For the field of optics, the event might be the casting of an 8-meter mirror, special laser surgery, the first light images of a telescope, or the etching of unique nanometer structures.

As an example of such a web-based event, a high-visibility event was created by San Francisco's Exploratorium (science center) around the total solar eclipse in Zambia that took place on June 21, 2001. The "Live from Africa" solar eclipse event was a great educational success. Sponsored by the Exploratorium and NASA's Sun-Earth Connection Education Forum, and endorsed by the National Society of Black Physicists, the hour-long program from Africa explained the science behind solar eclipses. In addition, the science of the active Sun was explored through imagery and videos from NASA solar missions such as SOHO and TRACE.

This event and others like it can serve as prototypes of web-based events hosted by science centers that are designed to reach large and geographically diverse audiences. Scientists play a very

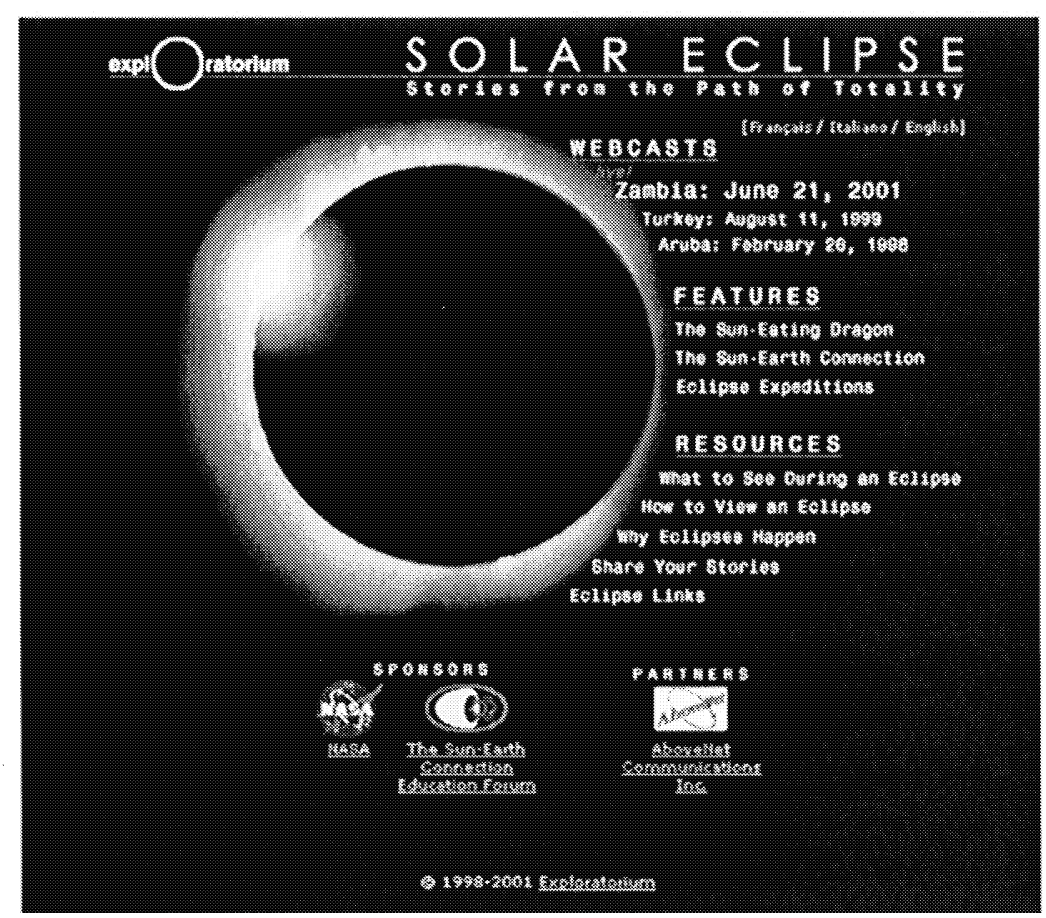


important role in these webcasts. They help develop the background material that can be posted on the web for reference. They also can provide live explanations and answer questions in the webcast. Scientists in different locations can also answer questions and do science demonstrations to a live audience at local institutions hosting the webcast. A great deal of advance planning is required to successfully create such an event.

This eclipse event had a very impressive reach:

- $\quad 42,000$ people participated at museums, science centers, and planetaria all over the world

- 164 organizations participated: 70 museums, planetariums, science institutions (21 international)

- 72 scientists participated

- 71 Girl Scout Troops (1 international)

- 15 Schools/universities (2 international)

- 2 Mass Media Groups (CNN and NASA TV/NASA Select)

- Exploratorium Eclipse Website statistics: 98,000 visits on June 21, 2001

$\sim 75$ million viewers: CNN, NBC Nightly News, NBC's Today show, Good Morning America, CBS's Newspath, NASA TV/NASA select, Fox News Tech TV Cable, NBC Network, ABC Network, CNBC Cable, and many local TV stations all over the US

$\sim 25$ million listeners: Radio interviews with scientists from the National Society of Black Physicists

$\sim 25$ million readers of national \& international newspapers and magazines

Though webcasts of this type have only been done in the last few years, it is likely that many more will take place over the next few years, and optics educators are looking for ways to use this medium.

\section{FINAL THOUGHTS ON WORKING WITH SCIENCE CENTERS}

Science Centers and other informal institutions are important avenues for increasing science literacy. Optics and photonics are natural topics that can be incorporated into science centers. Demonstrations and exhibits in this area can be very effective and highly illustrative of key scientific concepts. Science centers such as Flandrau Science Center in Tucson and the Lawrence Hall of Science in Berkeley have benefited greatly from collaborative efforts with scientists. Scientists who want to work effectively with science centers must try to accept the premise that science centers are the expert in presenting science to the public. While university scientists have considerable experience teaching students, they often have much less experience in working with young children, older adults or the general public. The education of these diverse groups may be considered specialties in themselves.

Science centers do work educationally; they make science interesting and can attract large audiences. Science center personnel have extensive experience in developing exhibits and programs. They are in contact with the public day after day. While they are enthusiastic about trying new approaches, they are not believers in magic bullets or that there are panaceas for the problem of scientific literacy.

With that in mind, the scientist can be an advocate for a variety of educational approaches that capture the full measure of the science and the process of science. Content specialty and process understanding represent the scientist's most precious areas of expertise. This collaboration between photonics scientists and science centers can be very fruitful if approached from a collegial perspective with respect for those in the science center, who perhaps have a more limited understanding of the science. Some scientists believe that working with graduate students and doing cutting edge science makes them a better educator than someone who works predominantly with children and doesn't have this extensive research background. On the contrary, someone who designs educational materials for children most certainly will have a better perspective on how to present that material to the public and perhaps a more profound understanding of misconceptions and other impediments to learning. 
Scientists should also pay particular attention to the power of the world-wide web and webcasts. They provide an effective way to reach large numbers of people worldwide and also provides a way for scientists to effectively use their specialized skills in a webcast. Webcasts also are cost-effective and educationally effective. Scientists should also be aware that yhere are professional organizations associated with natural history museums, children's museums, planetaria, and hands-on science technology centers. Organizations like the Association for Science and Technology Centers (ASTC), based in Washington D.C. ${ }^{3}$ can also be very useful in helping the scientist arrange collaborations with hands-on science centers.

\section{REFERENCES}

\footnotetext{
${ }^{1}$ Sheila. Grinell, A New Place for Learning Science, Association of Science-Technology Centers, 1992.

2 Victoria Newhouse, Towards a New Museum, The Monacelli Press, 1998.

${ }^{3}$ Association of Science-Technology Centers Incorporated, 1025 Vermont Avenue NW, Suite 500, Washington, DC 20005-3516

Telephone 202/783-7200, fax 202/783-7207, e-mail info@astc.org, web site www.astc.org
} 